\title{
Rous Sarcoma Virus
}

National Cancer Institute

\section{Source}

National Cancer Institute. Rous Sarcoma Virus. NCI Thesaurus. Code C14300.

A species of single-stranded, reverse-transcribing RNA retrovirus of the genus alpharetrovirus and the family retroviridae. It is the first oncovirus described in the literature and was found to cause sarcoma in chickens. 